Rev Inv Vet Perú 2021; 32(3): e18481

https://dx.doi.org/10.15381/rivep.v32i3.18481

\title{
Comunicación
}

\section{Aislamiento de Morganella morganii y Staphylococcus aureus en un paciente canino con lesión cutánea y de tejidos blandos: reporte de caso}

\author{
Isolation of Morganella morganii and Staphylococcus aureus in a canine patient \\ with skin and soft tissue injury: case report
}

\author{
María Camila Maldonado Vera ${ }^{1,3,}$ Cesar Calad Enríquez ${ }^{2}$
}

\section{Resumen}

Se presenta el caso clínico de un canino con pioderma profundo ulceroso con necrosis dérmica, donde se aísla Morganella morganii y Staphylococcus aureus de las lesiones cutáneas. El primero es una bacteria del medio ambiente y en la flora normal del tracto intestinal, y poco reportada en caninos. $S$. aureus es una bacteria estafilocócica grampositiva reconocida que se asocia con infecciones supurativas. Los resultados que abordan este estudio indican la importancia de llevar a cabo un rápido reconocimiento, diagnóstico e inicio de tratamiento basado en cultivos y antibiogramas. La infección polimicrobiana dificulta el tratamiento y su evolución, debiendo evitarse la progresión de lesiones en piel y enfermedades sistémicas secundarias.

Palabras clave: bacteria, perro, piel, necrosis, esfacelamiento

\footnotetext{
1 Pós-graduando do Departamento Clínica e Cirurgia Veterinária, Faculdade de Ciências Agrárias e Veterinárias (FCAV), Universidade Estadual Paulista «Júlio de Mesquita Filho» (UNESP), Campus Jaboticabal, Jaboticabal, SP, Brasil

2 Programa de Medicina Veterinaria, Universidad de Ciencias Aplicadas y Ambientales (U.D.C.A), Bogotá, Colombia

3 E-mail: mcmaldonado.mcmv@gmail.com; https://orcid.org/0000-0002-0979-0825
}

Recibido: 18 de agosto de 2020

Aceptado para publicación: 20 de febrero de 2021

Publicado: 23 de junio de 2021

CLos autores. Este artículo es publicado por la Rev Inv Vet Perú de la Facultad de Medicina Veterinaria, Universidad Nacional Mayor de San Marcos. Este es un artículo de acceso abierto, distribuido bajo los términos de la licencia Creative Commons Atribución 4.0 Internacional (CC BY 4.0) [https:// creativecommons.org/licenses/by/4.0/deed.es] que permite el uso, distribución y reproducción en cualquier medio, siempre que la obra original sea debidamente citada de su fuente original 
The clinical case of a canine with deep ulcerative pyoderma with dermal necrosis is presented, where Morganella morganii and Staphylococcus aureus were isolated from the skin lesions. The first is a bacterium from the environment and in the normal flora of the intestinal tract, and rarely reported in canines. S. aureus is a recognized gram-positive staphylococcal bacterium that is associated with suppurative infections. The results that address this study indicate the importance of carrying out a rapid recognition, diagnosis and initiation of treatment based on cultures and antibiograms. Polymicrobial infection makes treatment and its evolution difficult, and the progression of skin lesions and secondary systemic diseases must be avoided.

Key words: bacteria, dog, skin, necrosis, slough

\section{INTRODUCCIÓN}

Morganella morganii (M. morganii) es un bacilo gramnegativo perteneciente a la tribu Proteae de la familia Enterobacteriaceae y tiene dos subespecies, $M$. morganii y $M$. sibonii. Se encuentra en los tractos intestinales de humanos, mamíferos y reptiles como parte de la flora normal (Lin et al., 2015). Falagas et al. (2006) y Singla et al. (2010) indicaron que podría convertirse en un importante patógeno nosocomial oportunista asociándose principalmente con infecciones del tracto urinario, bacteriemia/sepsis, infecciones de piel y tejidos blandos, llegando hasta causar meningitis, alcanzando a generar consecuencias fatales. Sin embargo, en pacientes caninos son pocos los reportes de casos donde ha sido aislado; así, de Abreu Pereira et al. (2016) la reportaron en un caso de infección urinaria portador de uréter ectópico en un canino Bulldog Inglés, y de Oliveira et al. (2012) aislaron la bacteria en muestras de exudado etológico de perros con otitis.

En el estudio de Falagas et al. (2006) en humanos se aisló $M$. morganii en 9 de cada 13 pacientes con infecciones de piel y tejidos blandos, en conjunto con otros microorganismos como Staphylococcus aureus. Según Lipinska (2011), S. aureus es uno de los patógenos primarios más virulentos en humanos, causante de desde infecciones leves en piel hasta condiciones potencialmente mortales como la bacteriemia, endocarditis y sepsis. Tanto en caninos como en humanos, $S$. aureus es considerado como un importante agente etiológico en infecciones dérmicas superficiales y profundas, con tendencia al desarrollo de piodermas crónicos, que se tornen recurrentes y con predisposición a infecciones secundarias bacterianas (Principal et al., 2005). Sin embargo, según Duquette y Nuttall et al. (2004), esta no es la principal cepa estafilocócica en lesiones de piel y membranas mucosas, aunque ha sido establecida como patógeno importante colonizador en perros asociado frecuentemente con infecciones supurativas (Griffeth et al., 2008, Hoekstra y Paulton, 2002) y con piodermas (Malik et al., 2005).

Se han identificado 37 especies de estafilococos y todas son parte de la microflora normal de la piel y de las superficies mucosas del tracto respiratorio superior del hombre y los animales (Kaszanyitzky et al., 2003; Malik et al., 2005; Griffeth et al., 2008). No obstante, Griffeth et al. (2008) aislaron esta bacteria en $12 \%$ de pacientes ca- 
ninos con enfermedad inflamatoria de la piel y González et al. (2006) y Principal et al. (2005) la aislaron en casos de pioderma en perros. Esto indica la variedad de patógenos que pueden estar involucrados en lesiones cutáneas, y la importancia de realizar cultivos y antibiogramas en pacientes caninos con patologías como pioderma con el fin de aislar los patógenos causantes y poder realizar el un tratamiento adecuado.

Entre los tratamientos utilizados en lesiones extensivas de piel, según GonzálezDomínguez y Carmona (2014) se encuentra el extracto vegetal acuoso del Triticum vulgare, que estimula los procesos reparativos de la piel, la quimiotaxis y la maduración fibroblástica, y aumenta el índice fibroblástico, generando tejido de granulación además de tener una acción antibacteriana, sobre todo contra bacterias Gram negativas. Estos autores también mencionan la importancia de la implementación de vendajes para evitar la contaminación de la herida, evitando que la herida se seque.

En el presente estudio, se da a conocer un caso clínico donde se aíslan los patógenos $S$. aureus y $M$. morganii en paciente canino con pioderma profundo ulceroso con necrosis dérmica.

\section{Caso Clínico}

\section{Motivo de Consulta}

Llega a consulta un canino macho entero de raza Siberian Husky de 10 meses de edad, con peso de $22.5 \mathrm{~kg}$, porque presentaba dolor, inflamación y hematoma aproximadamente de $5 \times 5 \mathrm{~cm}$ a nivel axilar-costal del miembro anterior izquierdo (Figura 1), aumento de temperatura a nivel periférico de la lesión y claudicación $1 / 5$ de apoyo, temperatura corporal de $40.5^{\circ} \mathrm{C}$, frecuencia cardiaca de 120 latidos por minuto, frecuencia respiratoria de 40 respiraciones por minuto y pulso fuerte lleno y concordante.

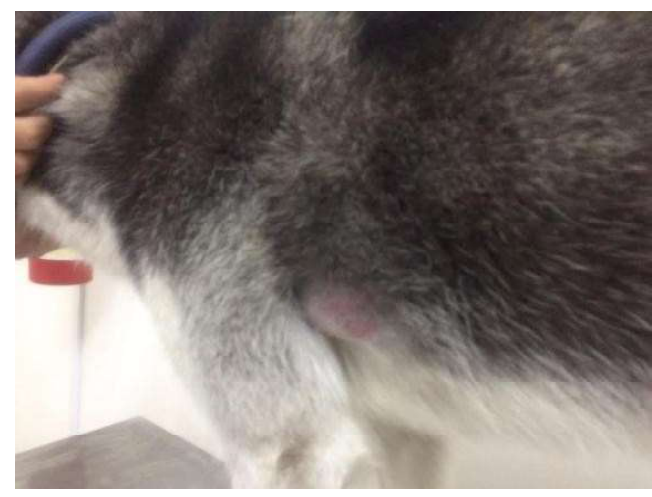

Figura 1. Presencia de hematoma a nivel axilar-costal del miembro anterior izquierdo en canino Siberian Husky de 10 meses

Con base en la información obtenida en la historia médica y el examen físico, se estableció como diagnósticos diferenciales trauma de tejidos blandos por contusión de segundo grado y absceso. Se procede a realizar cuadro hemático (Cuadro 1), radiografía de tórax laterolateral y ventro-dorsal (Figura 2).

Los resultados de hematología (Cuadro 1) muestran disminución de los valores de plaquetas (trombocitopenia o plaquetopenia), que pudo haber sido generado por el empleo en la extensa lesión de la piel; sin embargo, debido al histórico del paciente de asistir a una guardería campestre, estar en contacto constante con otros caninos sin control ni manejo preventivo de garrapatas y el aumento y oscilación de su temperatura corporal se sospechó de una posible hemoparasitosis. Además de esto, Acero et al. (2011) menciona un incremento en la zona de la prevalencia de hemoparásitos, lo que llevo a que los veterinarios afianzaran el diagnóstico diferencial de hemoparásitosis. Por otro lado, la serie de células blancas refleja leucocitosis con neutrofilia, lo que indica la presencia de un proceso infeccioso bacteriano de evolución aguda, así como un proceso de respuesta inflamatoria. 
Cuadro 1. Resultados de la hematología completa en el paciente canino Siberian Husky de 10 meses (Resultado 1; muestro inicial; Resultado 2; Control cinco días después)

\begin{tabular}{lccc}
\hline \multicolumn{1}{c}{ Parámetro } & Resultado 1 & Resultado 2 & Referencia $^{1}$ \\
\hline Eritrograma & & & \\
Eritrocitos (x10/ml) & 6.08 & 6.19 & $5.5-8.5$ \\
Hemoglobina (mg/dl) & 15.50 & 16 & $12-18$ \\
VCM (fl) & 72 & 69 & $60-75$ \\
Hematocrito (\%) & 43.56 & 42.88 & $37-55$ \\
CHMH (\%) & 35.70 & 37.20 & $32-36$ \\
Ancho dis. eritrocitario (\%) & 14.80 & 15.10 & $12-15$ \\
Trombograma & & & \\
Plaquetas (/ml) & 116,000 & 76,000 & $2,000,000$ \\
& & & $-500,000$ \\
VPM (fl) & 14.3 & 13.7 & $6.7-11.1$ \\
Leucograma & & & \\
Leucocitos (/ml) & 35,000 & 38,000 & $6,000-17,000$ \\
Neutrófilos $(/ \mathrm{ml})$ & 3,000 & 34,000 & $3,000-11,500$ \\
Linfocitos $(/ \mathrm{ml})$ & 2,000 & 1,000 & $1,000-4,800$ \\
\hline
\end{tabular}

${ }^{1}$ Rizzi et al. 2010

Las radiografías de tórax (Figura 2) evidencian aumento de tamaño en tejido blando de zona costo-axilar izquierda, sin evidencia de lesión en cavidad torácica.

\section{Manejo Terapéutico y Evolución Clínica}

Para mitigar el dolor se administra Dipirona a $25 \mathrm{mg} / \mathrm{kg}$ vía IV única dosis, tramadol $3 \mathrm{mg} / \mathrm{kg}$ dos veces al día vía $\mathrm{SC}$, suplementación con Aminolite $5 \mathrm{ml} / \mathrm{kg}$ vía IV dos veces al día; y para la inflamación y dolor a nivel tópico se adicionan paños de sulfato de magnesio 4 veces al día más Diclofenaco en gel tres veces al día de forma tópica y alimentación con dieta húmeda tres veces al día.
Al trascurrir la evolución intrahospitalaria, se evidencia hematoma e inflamación y acúmulo de líquidos en zona costo-abdominal izquierda y codo del miembro anterior izquierdo, desencadenando una claudicación $3 / 5$ mixta. Debido a este cuadro clínico la piel de la zona afectada empezó a necrosarse, a tornarse friable y desvitalizada, generando ruptura y a esfacelarse (Figura 3 ).

El paciente inicia defecaciones diarreicas, por lo que se toma una muestra de heces para examen coprológico. Se encontró aumento de flora bacteriana, estructuras compatibles con Campylobacter sp, trofozoitos y quistes de Giardia sp (+++), dificultando 

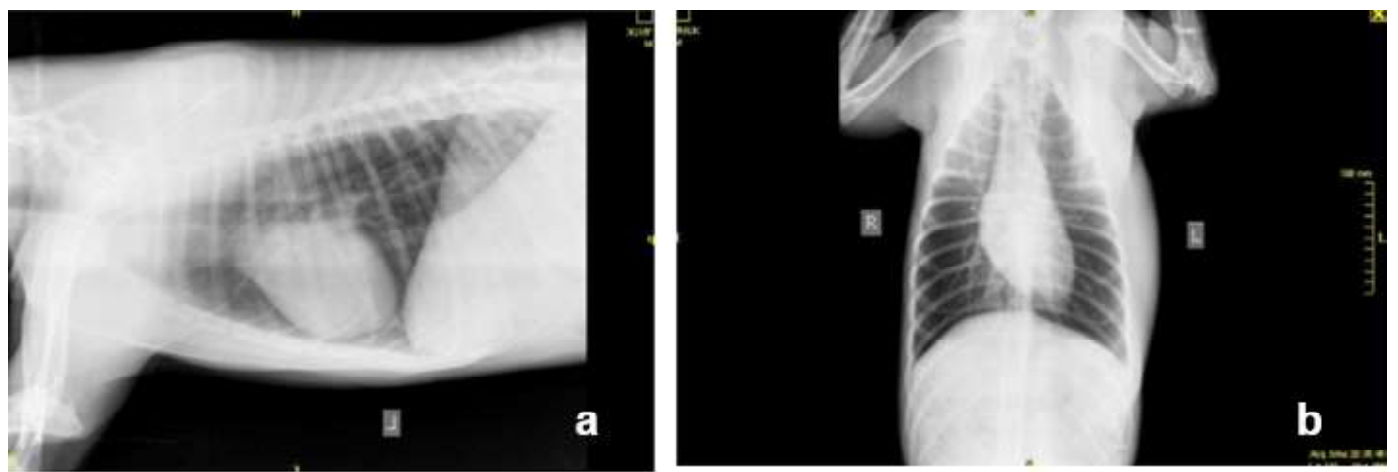

Figura 2. Radiografías vistas a) laterolateral y b) ventro-dorsal de tórax de canino Siberian Husky de 10 meses

la evolución del cuadro clínico de piel y empeorando el pronóstico del paciente. Ante esto, se instaura Carprofeno a dosis de 2.2 $\mathrm{mg} / \mathrm{kg}$ una vez al día vía $\mathrm{SC}$ como antiinflamatorio no esteroidal, antibioticoterapia con amoxicilina más ácido clavulánico a dosis de $8.7 \mathrm{mg} / \mathrm{kg}$ una vez al día vía SC para contrarrestar la infección de piel y tejidos blandos, Bismo pet (subsalicilato de bismuto) $15 \mathrm{ml}$ dosis total dos veces al día vía oral como antidiarreico, Ondancetron a dosis de $0.011 \mathrm{mg} / \mathrm{kg}$ dos veces al día vía IV usado en la prevención de náuseas y vómitos, y como antibióticos gastrointestinales, Metronidazol a $15 \mathrm{mg} / \mathrm{kg}$ dos veces al día vía IV, además de ser utilizado como antiprotozoario y eritromicina a dosis de $10 \mathrm{mg} / \mathrm{kg}$ dos veces al día vía oral.

Se toma una segunda muestra de sangre cinco días después (Cuadro 1) encontrando una acentuación de la trombocitopenia, lo cual permite sospechar como diagnóstico diferencial de hemoparásitos. Por lo tanto, se realiza un extendido en lámina de sangre periférica el cual resultó negativo para hemoparásitos. Sin embargo, debido al histórico del paciente y la continua disminución de plaquetas, no se descarta la enfermedad y se administra atropina a dosis de $0.20 \mathrm{mg} / \mathrm{kg}$ vía $\mathrm{SC}$, y 10 minutos después Dipropionato de Imidocarb (imizol) a dosis de $5 \mathrm{mg} / \mathrm{kg}$ vía SC.

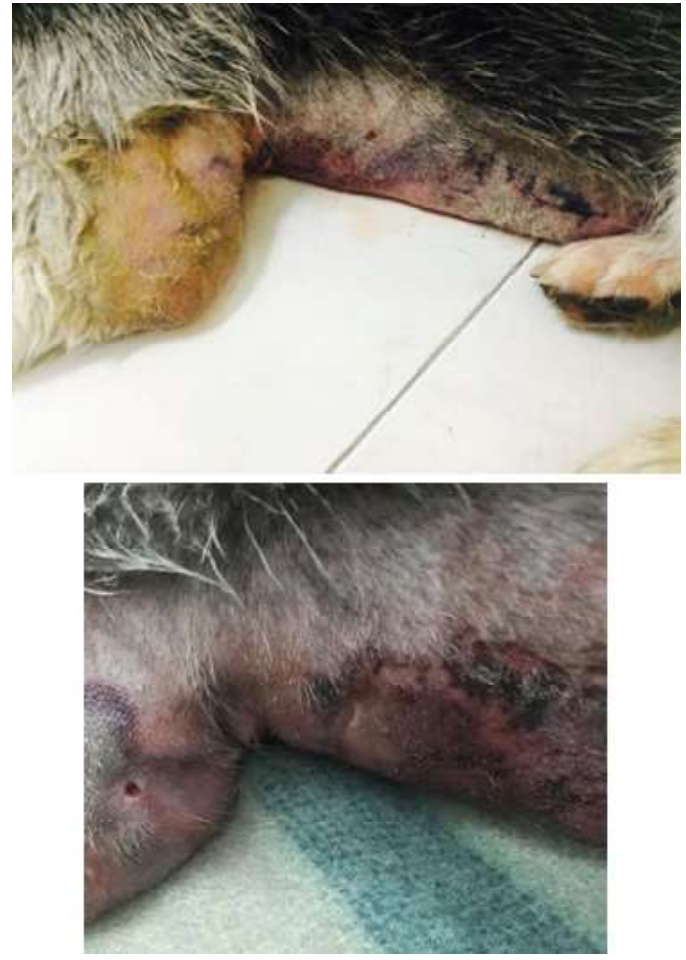

Figura 3. Involución de la lesión de piel (necrosis, desvitalización)

Debido al cuadro clínico y la involución y necrosis de la piel, se decide realizar sedación al paciente y hacer lavados a profundidad en las zonas afectadas. En el quirófano, el tejido se encontraba friable, desvitalizado 
Cuadro 2. Resultados del antibiograma del paciente canino Siberian Husky de 10 meses con necrosis de piel

\begin{tabular}{llll}
\hline \multicolumn{2}{c}{ Morganella morganii } & \multicolumn{2}{c}{ Staphylococcus aureus } \\
\hline Resistente & Sensible & Resistente & Sensible \\
\hline Trimetropin sulfa & $\begin{array}{l}\text { Amoxicilina ácido } \\
\text { clavulánico }\end{array}$ & Meticilina & $\begin{array}{l}\text { Amoxicilina ácido } \\
\text { clavulánico }\end{array}$ \\
Cefalexina & Clindamicina & Ampicilina & Clindamicina \\
Gentamicina & Oxitetraciclina & Trimetropin sulfa & Oxitetraciclina \\
Ampicilina & Norfloxacina & Cloxacilina & Cefalexina \\
Penicilina & Ceftazidina & Cloranfenicol & Gentamicina \\
Enrrofloxacina & Imipenem & Vancomicina & Bacitracina \\
& & Penicilina & Eritromicina \\
\hline
\end{tabular}

Laboratorio R\&M Veterinaria (Bogotá)

y necrosado, conllevando a la pérdida de este en su totalidad (zona costo- abdominal, pectoral, codo y parte dorsal de miembro anterior izquierdo). Se evidencia mal olor y secreciones putrefactas (Figura 4), por lo que se realiza cultivo y antibiograma (Cuadro 2). Se procede a realizar lavado y reavivamiento de bordes (Figura 5) para evitar una mayor infección necrosante de tejidos blandos o fascitis necrotizante. Posteriormente, se instauran apósitos en el tejido expuesto, vendajes semicompresivos (Figura 6) y se adi- ciona infusión analgésica. Los resultados de las muestras analizadas por el laboratorio $\mathrm{R} \& \mathrm{M}$ Veterinaria (Bogotá) indicó las bacterias $M$. morganii y $S$. aureus.

Debido a los resultados obtenidos del cultivo y antibiograma, se adiciona al tratamiento clindamicina a dosis de $10 \mathrm{mg} / \mathrm{kg}$ vía IV 3/día, oxitetraciclina a dosis de $10 \mathrm{mg} / \mathrm{kg}$ vía IV 2/día y se realizaron limpiezas a profundidad con gasa y cloruro de sodio $(\mathrm{NaCl}$ al $0.9 \%$ ) de 12 veces al día y posteriormente
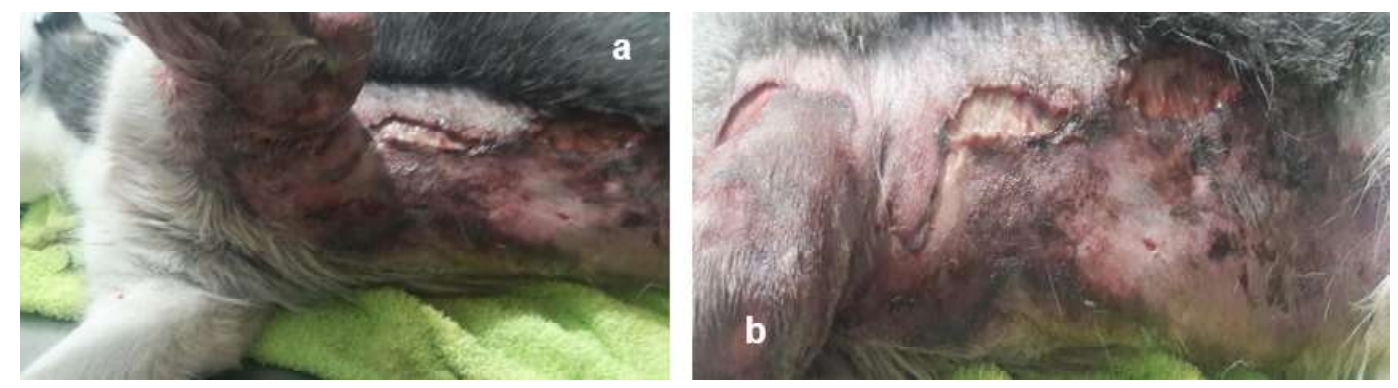

Figura 4. Secreciones putrefactas. ruptura y desprendimiento de la piel en paciente canino de 10 meses. a) zona costal izquierda b) zona abdominal izquierda 

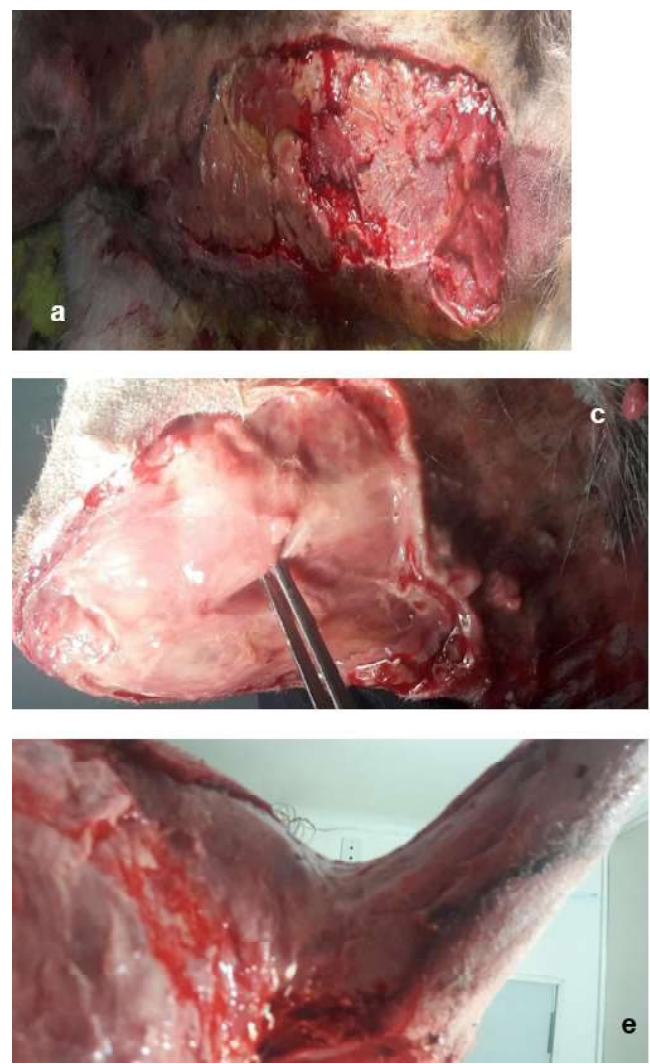
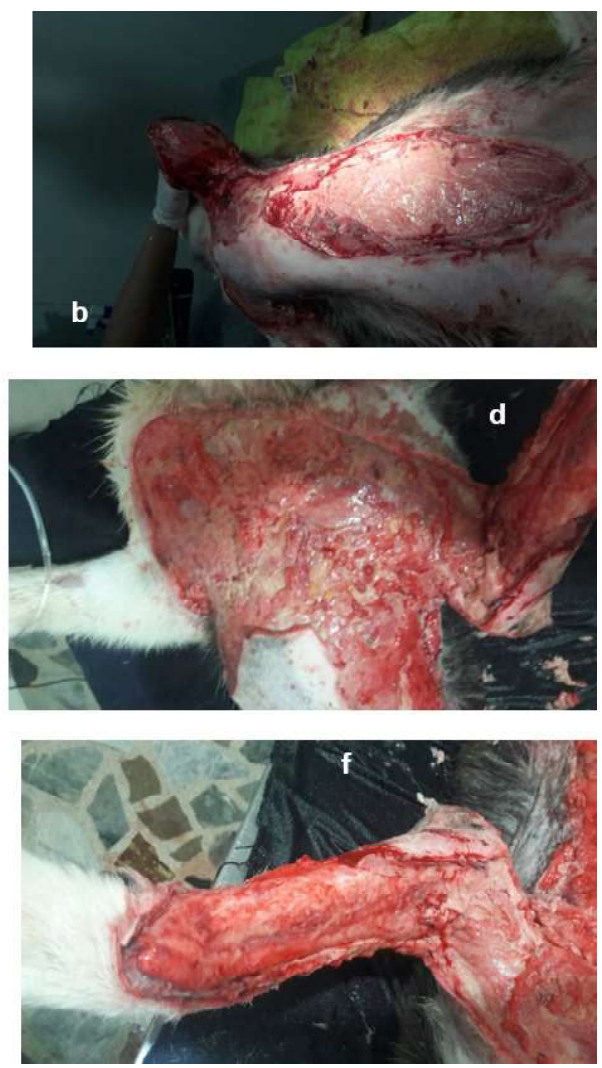

Figura 5. Paciente canino Siberian Husky de 10 meses con necrosis de piel. a), b) Lavado y reavivamiento de bordes de la zona costo- abdominal; d) codo; e), f) parte dorsal de miembro anterior izquierdo

se instauró Fitoestimline (Triticum Vulgare +2 Fenoxietanol) en gel o en gasa más vendajes semi compresivos hasta lograr el cierre total de las lesiones en piel (Figura7).

\section{Discusión}

En el cultivo realizado al paciente se aislaron las bacterias $M$. morganni y $S$. aureus. La primera es una bacteria que forma parte de la flora normal del tracto intestinal (Lin et al., 2015), por lo que es posible encontrarla en lugares donde hay disposición de heces (Pozo et al., 1998), pudiendo generar una infección oportunista en el paciente canino. Una hipótesis de la posible contaminación del perro y consecuente cuadro clínico es que, según el propietario, el paciente frecuentaba una guardería donde el área social de los perros era cercana a una vertiente de aguas negras a la cual tenían acceso.

Se reporta que en el $69 \%$ de pacientes humanos con lesiones de piel y tejidos blandos, donde se ha aislado M. morganii es polimicrobiano (Falagas et al., 2006; Lin et al., 2015); es decir están acompañadas de otros microorganismos y uno de estos agentes fue $S$. aureus. En perros, S. aureus a pesar de que no es la cepa estafilocócica de mayor aislamiento en lesiones de piel y membranas mucosas (Duquette y Nuttall et al., 2004), es un importante agente etiológico en infecciones dérmicas, tanto superficiales 

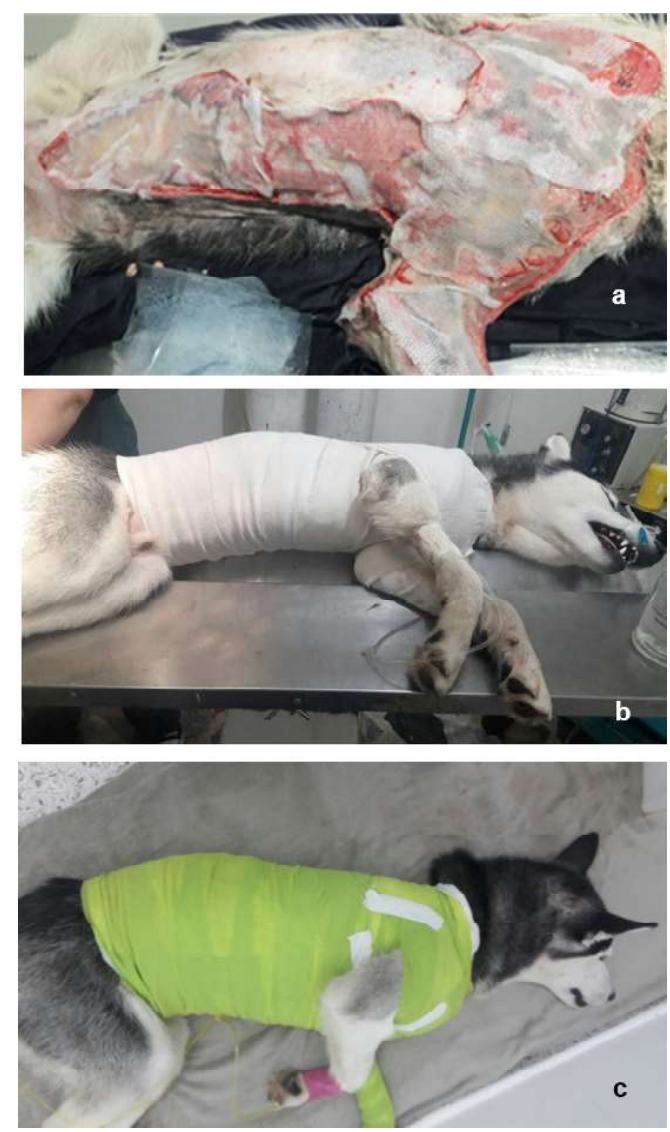

Figura 6. Instauración de apósitos en el tejido expuesto y vendajes semi compresivos en paciente canino Siberian Husky de 10 meses con necrosis de piel. a) gel o gasa de Fitoestimuline ${ }^{\circledR}$ b) capa venda de gasa c) capa con vendaje elástico

como profundas (Principal et al., 2005) asociado con infecciones supurativas (Hoekstra y Paulton, 2002; Griffeth et al., 2008) y con piodermas (Malik et al., 2005), lo que demuestra la importancia de realizar el cultivo y el antibiograma.

Al tratarse de infecciones polimicrobianas, y teniendo en cuenta los resultados del cultivo y antibiograma, se realizaron combinaciones de antibióticos (amoxicilina más ácido clavulánico, eritromicina, clindamicina y oxitetraciclina), lo cual está de acuerdo con lo relatado por Falagas et al. (2006). Según Falagas et al. (2006) y Lin et al. (2015), en infecciones por M. morganii se puede administrar antibióticos betalactámicos, algunos derivados de penicilina (amoxicilina) y la combinación de amoxicilina con ácido clavulánico. Esta última es también indicada en infecciones por $S$. aureus (DeBoer, 1990; Duquette y Nuttall, 2004). Por otro lado, el uso de los macrólidos, como la eritromicina y las lincosamidas como la clindamicina se consideran opciones razonables para el tratamiento de primera línea de los piodermas caninos causados por estafilococos, ya que tienen buena absorción oral, distribución tisular y alta concentración intracelular (Ganiere et al., 2005).

Una vez que las lesiones de piel se expanden y generan necrosis profundas se debe realizar un desbridamiento constante por periodos prolongados evitando la presentación de sepsis (Bagel y Grossman, 1985). La primera línea de tratamiento requiere incisión, drenaje y subsecuente terapia antimicrobial 

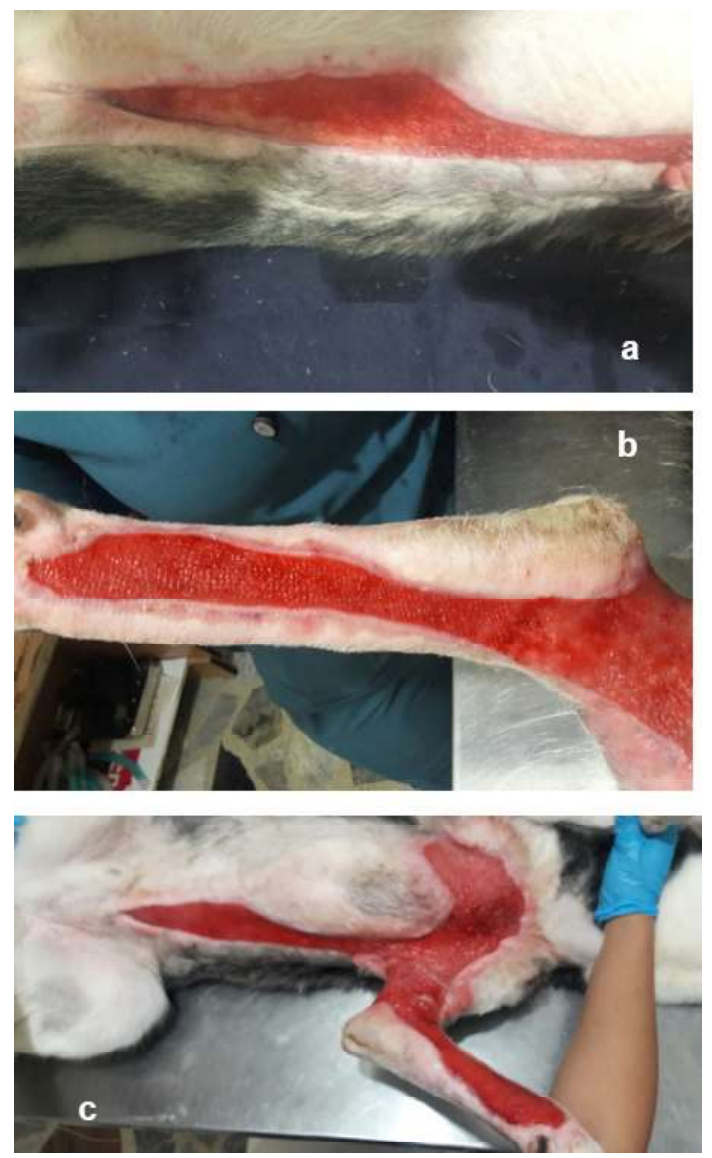

Figura 7. Paciente canino Siberian Husky de 10 meses con necrosis de piel. Evolución de las lesiones del tejido con limpiezas, uso de Fitoestimuline ${ }^{\circledR}$ y vendajes semi compresivos. a) zona costo-abdominal; b) miembro anterior izquierdo; c) vista general

(Iyer y Jones, 2004), tal y como se realizó en el paciente, con limpiezas a profundidad con solución salina al $0.9 \%$ (Figura 5). Para facilitar una pronta recuperación y un efecto estético satisfactorio es necesario promover un ambiente húmedo que permita la migración celular y la formación de una cicatriz normotrófica, lo cual se logró con Fitoestimuline (Triticum vulgare +2 Fenoxietanol) con vendajes semicompresivos (Figura 6). Triticum sp, principal componente del ungüento utilizado en este caso contiene fitoestimulinas que actúan sobre los fibroblastos ejerciendo un efecto mitogénico y estimulando su capacidad para sintetizar colágeno y glicosaminoglicano, induciendo un proceso de curación que estimula una mayor fuerza tensiométrica (Tillmann et al., 2014). Según Souza et al. (2006), el uso de las cremas a base de T. vulgare mejora la cicatrización de las heridas aumentando la neoformación de vasos sanguíneos, teniendo una acción positiva en el proceso de cicatrización. En este caso, el uso de este producto favoreció la evolución en la cicatrización, formación de tejido de granulación y cierre de la herida del paciente.

La trombocitopenia observada (Cuadro 1) permitió la sospecha de hemoparásitos (Bulla et al., 2004). Además, da Silva et al. (2012) indican que la infección causada por 
Erlichia canis y Anplasma platys son causa importante de anemia y trombocitopenia en perros. En este caso el examen de frotis de sangre periférica resultó negativo; no obstante, teniendo en consideración la baja sensibilidad y especificidad diagnóstica de esta prueba, no se descartó por completo la presencia de la enfermedad, de allí que se administró atropina y dipropionato de imidocarb (imizol) según lo descrito por Figueiredo (2011).

\section{Literatura Citada}

1. Acero E, Calixto O, Prieto A. 2011. Garrapatas (Acari: Ixodidae) prevalentes en caninos no migrantes del noroccidente de Bogotá, Colombia. Nova 9: 158-165. doi.org/10.22490/24629448.498

2. Bagel J, Grossman ME. 1985. Hemorrhagic bullae associated with Morganella morganii septicemia. J Am Acad Dermatol 12: 575-576. doi: 10.1016/s0190-9622(85)70082-5

3. Bulla C, Kiomi Takahira R, Pessoa Araújo J, AparecidaTrinca L, Souza Lopes R, Wiedmeyer CE. 2004. The relationship between the degree of thrombocytopenia and infection with Ehrlichia canis in an endemic area. Vet Res 35: 141-146. doi: 10.1051/ vetres: 2003038

4. da Silva GC, Benitez AN, Girotto AT, Vidotto MC, Garcia JL, Freitas JC, Headley AS, et al. 2012. Occurrence of Ehrlichia canis and Anaplasma platys in household dogs from northern Parana. Rev Bras Parasitol V 21: 379385. doi: 10.1590/S1984-29612012005000009

5. de Abreu Pereira J, Bonci MM, Botteon RC, de Souza MM, da Veiga CC, da Costa A. 2016. Infecção urinária por Morganella morganii em cão jovem portador de ureter ectópico. Acta Vet Bras 10: 273-277
6. de Oliveira $V$, Ribeiro $M$, da Silva Almeida A, Paes A, Condas L, Lara G, Franco MM, et al. 2012. Etiologia, perfil de sensibilidade aos antimicrobianos e aspectos epidemiológicos na otite canina: estudo retrospectivo de 616 casos. Semin-Cienc Agrar 33: 2367-2374. Doi: $10.5433 / 1679-0359.2012$ v33n6p2367

7. DeBoer DJ. 1990. Strategies for management of recurrent pyoderma in dogs. Vet Clin N Am-Small 20: 15091524. doi: 10.1016/s0195-5616(90)50158-8

8. Del Pozo J, García-Silva J, Almagro M, Martínez W, Nicolas $R$, Fonseca E. 1998. Ecthyma gangrenosum-like eruption associated with Morganella morganii infection. Br J Dermatol 139: 520-521. doi: 10.1046/j.1365-2133.1998.02423.x

9. Duquette RA, Nuttall TJ. 2004. Methicillin-resistant Staphylococcus aureus in dogs and cats: an emerging problem? J Small Anim Pract 45: 591597. doi: 10.1111/j.1748-5827.2004.tb00180.x

10. Falagas ME, Kavvadia PK, Mantadakis E, Kofteridis DP, Bliziotis IA, Saloustros E, Maraki S, et al. 2006. Morganella morganii infections in a general tertiary hospital. Infection $34: 315-$ 321. doi: 10.1007/s15010-006-6682-3

11. Figueiredo MR. 2011. Babesiose e erliquiose caninas. Trabalho de Especialista. Rio de Janeiro. 39 p.

12. Ganiere JP, Medaille C, Mangion $C$. 2005. Antimicrobial drug susceptibility of Staphylococcus intermedius clinical isolates from canine pyoderma. $\mathrm{J}$ Vet Med B 52: 25-31. doi: 10.1111/j.14390450.2004.00816.x

13. González-Domínguez MS, Carmona S. 2014. Using Triticum vulgare in postsurgical treatment of chronic fibrosing interdigital pyoderma in a dog. Case report. CES Med Vet Zootecv 9: 128-138. 
14. González JL, Bravo V, Peña A, Beral M. 2006. Dermatología. Eficacia terapéutica del orifloxacino (Orbax) en el tratamiento de la pioderma canina: un estudio cínico abierto. Clin Vet Pequeños An 26: 9-12.

15. Griffeth GC, Morris DO, Abraham JL, Shofer FS, Rankin SC. 2008. Screening for skin carriage of methicillinresistant coagulase-positive staphylococci and Staphylococcus schleiferi in dogs with healthy and inflamed skin. Vet Dermatol 19: 142-149. doi: 10.1111/ j.1365-3164.2008.00663.x

16. Hoekstra KA, Paulton RJ. 2002. Clinical prevalence and antimicrobial susceptibility of Staphylococcus aureus and Staph. intermedius in dogs. J Appl Microbiol 93: 406-413. doi: 10.1046/ j.1365-2672.2002.01708.x

17. Iyer S, Jones DH. 2004. Communityacquired methicillin-resistant Staphylococcus aureus skin infection: a retrospective analysis of clinical presentation and treatment of a local outbreak. J Am Acad Dermatol 50: 854-858. doi: 10.1016/j.jaad.2003.12.043

18. Kaszanyitzky EJ, Jánosi S, Egyed Z, Agost G, Semjén G. 2003. Antibiotic resistance of staphylococci from humans, food and different animal species according to data of the Hungarian resistance monitoring system in 2001. Acta Vet Hung 51: 451-464. doi: 10.1556/AVet.51.2003.4.3

19. Lin TY, Chan MC, Yang YS, Lee Y, Yeh KM, Lin JC, Chang FY. 2015. Clinical manifestations and prognostic factors of Morganella morganii bactere-mia. Eur J Clin Microbiol 34: 231236. doi: $10.1007 / \mathrm{s} 10096-014-2222-8$
20. Lipinska U, Hermans K, Meulemans L, Dumitrescu O, Badiou C, Duchateau L, Haesebrouck F, et al. 2011. Panton-Valentine leukocidin does play a role in the early stage of Staphylococcus aureus skin infections: a rabbit model. Plos One 6: e22864. doi: 10.1371/ journal.pone.0022864

21. Malik S, Peng H, Barton MD. 2005. Antibiotic resistance in staphylococci associated with cats and dogs. J Appl Microbiol 99: 1283-1293. doi: 10.1111/ j.1365-2672.2005.02699.x

22. Principal J, Barrios C, Tahís Pacheco $N$, Corrales F, Moreno F. 2005. Actividad antibacteriana in vitro del extracto etanólico de propóleo sobre una cepa clínica de Staphylococcus aureus. Gaceta Cienc Vet 11: 31-36.

23. Rizzi TE, Meinkoth JH, Clinkenbeard KD. 2010. Normal hematology of the dog. In: Schalm's veterinary hematology p 799-810.

24. Singla N, Kaistha N, Gulati N, Chander J. 2010. Morganella morganii could be an important Intensive Care Unit pathogen. Indian J Crit Care Med 14: 154-155. doi: 10.4103/09725229.74176

25. Souza D, Machado T, Zoppa A, Cruz $R$, Garague A, Silva L. 2006. Ensaio da aplicacao de creme a base de Triticum vulgare na cicatrizacao de feridas cutaneas induzidas em equinos. Rev Bras Plantas Med 8: 9-13.

26. Tillmann MT, Felix AO, Mueller EN, Felix SR, Alves GH, Ramos TS, Freitag $R A$, et al. 2014. Use of Triticum aestivum in open wound healing: a clinical, pathological, and tensiometric assessment in the rabbit model. Arq Bras Med Vet Zoo 66: 17571761. doi: 10.1590/1678-7132 